\title{
Complete genome sequence of Intrasporangium calvum type strain (7 KIP')
}

Tijana Glavina Del Rio ${ }^{1}$, Olga Chertkov ${ }^{1,2}$, Montri Yasawong ${ }^{3}$, Susan Lucas ${ }^{1}$, Shweta Deshpande ${ }^{1}$, Jan-Fang Cheng ${ }^{1}$, Chris Detter ${ }^{1,2}$, Roxanne Tapia ${ }^{1,2}$, Cliff Han ${ }^{1,2}$, Lynne Goodwin $^{1,2}$, Sam Pitluck ${ }^{1}$, Konstantinos Liolios ${ }^{1}$, Natalia Ivanova ${ }^{1}$, Konstantinos Mavromatis ${ }^{1}$, Amrita Pati ${ }^{1}$, Amy Chen ${ }^{4}$, Krishna Palaniappan ${ }^{4}$, Miriam Land ${ }^{1,5}$, Loren Hauser $^{1,5}$, Yun-Juan Chang ${ }^{1,5}$, Cynthia D. Jeffries ${ }^{1,5}$, Manfred Rohde ${ }^{3}$, Rüdiger Pukall ${ }^{6}$, Johannes Sikorski ${ }^{6}$, Markus Göker ${ }^{6}$, Tanja Woyke ${ }^{1}$, James Bristow ${ }^{1}$, Jonathan A. Eisen ${ }^{1,7}$, Victor Markowitz ${ }^{4}$, Philip Hugenholtz ${ }^{1}$, Nikos C. Kyrpides ${ }^{1}$, Hans-Peter Klenk ${ }^{6}$, and Alla Lapidus $^{1 *}$

${ }^{1}$ DOE Joint Genome Institute, Walnut Creek, California, USA

${ }^{2}$ Los Alamos National Laboratory, Bioscience Division, Los Alamos, New Mexico, USA

${ }^{3}$ HZI - Helmholtz Centre for Infection Research, Braunschweig, Germany

${ }^{4}$ Biological Data Management and Technology Center, Lawrence Berkeley National Laboratory, Berkeley, California, USA

${ }^{5}$ Oak Ridge National Laboratory, Oak Ridge, Tennessee, USA

${ }^{6}$ DSMZ - German Collection of Microorganisms and Cell Cultures GmbH, Braunschweig, Germany

${ }^{7}$ University of California Davis Genome Center, Davis, California, USA

${ }^{*}$ Corresponding author: Alla Lapidus

Keywords: airborne, Gram-positive, non-motile, intercalary vesicles, nocardioform, Actinobacteria, Intrasporangiaceae, GEBA

Intrasporangium calvum Kalakoutskii et al. 1967 is the type species of the genus Intrasporangium, which belongs to the actinobacterial family Intrasporangiaceae. The species is a Grampositive bacterium that forms a branching mycelium, which tends to break into irregular fragments. The mycelium of this strain may bear intercalary vesicles but does not contain spores. The strain described in this study is an airborne organism that was isolated from a school dining room in 1967. One particularly interesting feature of I. calvum is that the type of its menaquinone is different from all other representatives of the family Intrasporangiaceae. This is the first completed genome sequence from a member of the genus Intrasporangium and also the first sequence from the family Intrasporangiaceae. The 4,024,382 bp long genome with its 3,653 protein-coding and 57 RNA genes is a part of the Genomic Encyclopedia of Bacteria and Archaea project.

\section{Introduction}

Strain 7 KIPT $^{\text {T }}$ = DSM $43043=$ ATCC $23552=$ JCM 3097 ) is the type strain of the species Intrasporangium calvum, which is the type species of its genus Intrasporangium $[1,2]$. The generic name derived from the Latin word intra meaning within and the Greek word spora meaning a seed. The name Intrasporangium, was selected to emphasize the possibility of intercalary formation of sporangia in mycelial filaments [3]. Intrasporangium is the type genus of the family Intrasporangiaceae and one out of currently nineteen genera in the family Intrasporangiaceae [4-6]. Strain $7 \mathrm{KIP}^{\mathrm{T}}$ was first described in 1967 by Kalakoutskii et al. as an airborne organ- ism, which was isolated under nonselective conditions on plates of meat-peptone agar exposed to the atmosphere of a school dining room $[1,7,8]$. I. cal$v u m$ is of particular interest because the type of its menaquinones is different from all other representatives of the family Intrasporangiaceae [8]. Here we present a summary classification and a set of features for I. calvum 7 KIPT, together with the description of the complete genomic sequencing and annotation. 


\section{Classification and features}

The 16S rRNA gene of strain $7 \mathrm{KIPT}^{\mathrm{T}}$ shares 92.6$98.7 \%$ sequence identity with the sequences of the type strains from the other members of the family Intrasporangiaceae [9], with Humihabitans oryzae as the closest relative. The $16 \mathrm{~S}$ rRNA gene sequence of $7 \mathrm{KIP}^{\mathrm{T}}$ is $99 \%$ identical to the uncultured Intrasporangiaceae clone HT06Ba24, isolated from soil of a former coal gasification site in Gliwice, Poland $[10,11]$ and AKAU4164, isolated from uranium contaminated soil in Oak Ridge, USA $[10,12]$. The environmental samples database (env_nt) contains the marine metagenome clone 1096626841081 (AACY020552144) from surface water (92\% sequence identity with $7 \mathrm{KIP}^{\mathrm{T}}$ ). The genomic survey sequences database (gss) contains the metagenomic clone 1061002660518 from Floreana island in Punta Cormorant, Ecuador [10], which shares 93\% sequence identity with $7 \mathrm{KIP}^{\mathrm{T}}$ (as of July 2010). One of the 16S rRNA sequences of strain $7 \mathrm{KIP}^{\mathrm{T}}$ was compared using NCBI BLAST under default values (e.g., considering only the best 250 hits) with the most recent release of the Greengenes database [13] and the relative frequencies, weighted by BLAST scores, of taxa and keywords, weighted by BLAST scores, were determined. The five most frequent genera were Janibacter (29.6\%), Terrabacter (19.8\%), Sanguibacter (8.4\%), Dermacoccus (7.7\%) and Tetrasphaera (6.2\%). The five most frequent keywords within the labels of environmental samples which yielded hits were 'skin' (9.1\%), 'human' (4.7\%),'microbiome/temporal/topographical' (4.5\%), 'sludge' (4.4\%) and 'heel/plantar' (3.1\%). The single most frequent keyword within the labels of environmental samples which yielded hits of a higher score than the highest scoring species was 'contaminated/soil/uranium' (33.3\%).

Figure 1 shows the phylogenetic neighborhood of I. calvum $7 \mathrm{KIP}^{\mathrm{T}}$ in a $16 \mathrm{~S}$ rRNA based tree. The sequences of the two 16S rRNA gene copies in the genome are differ by only one nucleotide from each other and by up to one nucleotide from the previously published sequence generated from DSM 43043 (AJ566282).

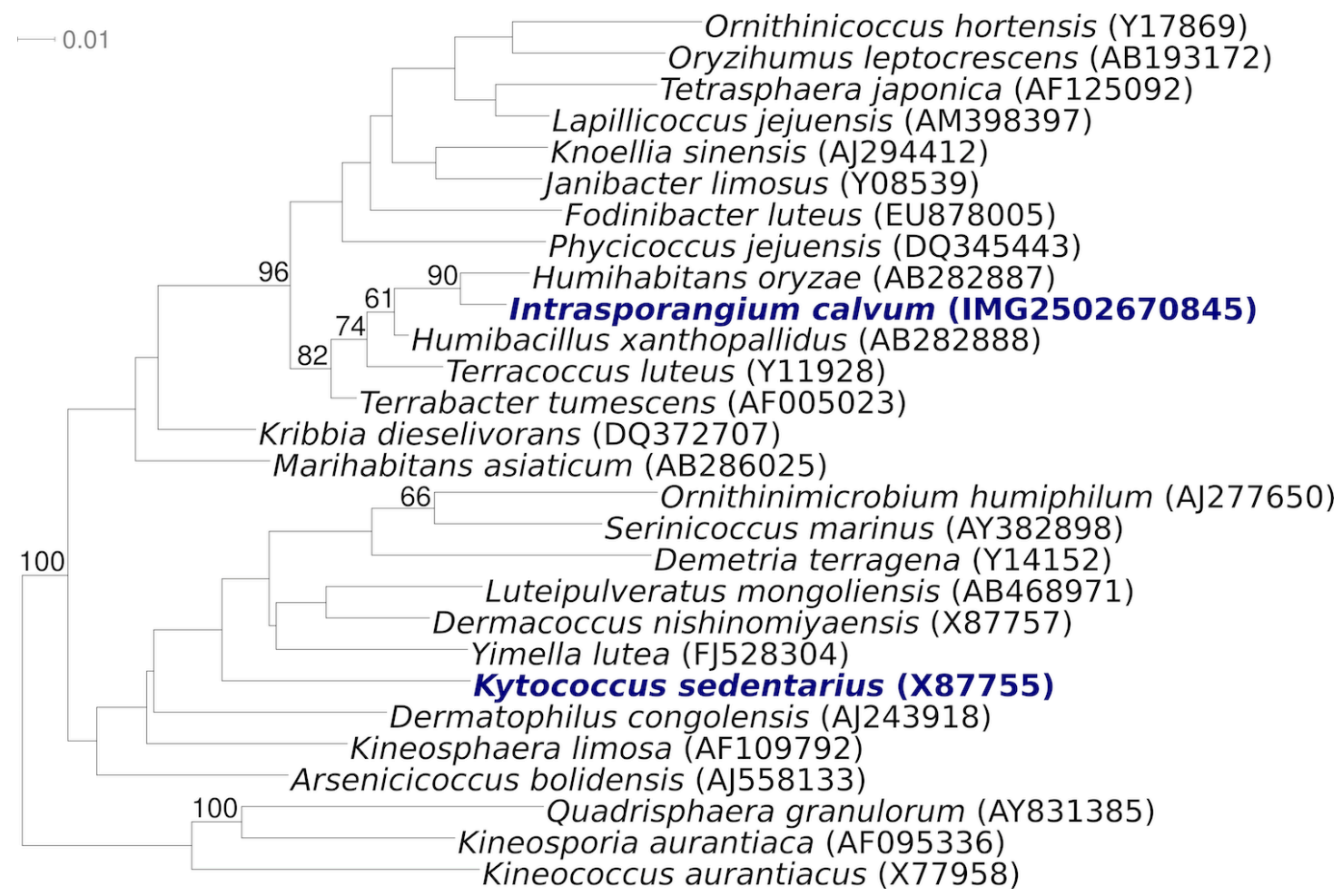

Figure 1. Phylogenetic tree highlighting the position of $I$. calvum $7 \mathrm{KIP}^{\top}$ relative to the type strains of the genera within the family Intrasporangiaceae. The trees were inferred from 1,406 aligned characters $[14,15]$ of the $16 \mathrm{~S}$ rRNA gene sequence under the maximum likelihood criterion [16] and rooted with the type strains of the genera within the family Kineosporiaceae [17]. The branches are scaled in terms of the expected number of substitutions per site. Numbers above branches are support values from 650 bootstrap replicates [18] if larger than 60\%. Lineages with type strain genome sequencing projects registered in GOLD [19] are shown in blue, published genomes in bold [20]. 
Strain 7 KIPT $^{\mathrm{T}}$ forms a branching mycelium, which tends to break into irregular fragments, i.e., typically nocardioform $[1,8]$. The mycelium may bear intercalary vesicles that do not contain spores [Table 1, Figure $2,7,26]$. The vesicles of strain $7 \mathrm{KIP}^{\mathrm{T}}$ are ovoid and lemon-shaped (5-15 $\mu \mathrm{m}$ in diameter) [1,7]. Several round or oval bodies (1.2-1.5 $\mu \mathrm{m}$ in diameter) may be observed in the vesicles of older cultures $[1,7]$. The oval bodies in the vesicles of strain 7 KIPT are nonmotile but may undergo a Brownian movement (in mature vesicles) [1,7]. There was no aerial mycelium observed from the strain $7 \mathrm{KIP}^{\mathrm{T}}[1,7,8]$. The mycelial filaments penetrate the agar and form compact, small colonies (1-5 mm of diameter) [1]. These colonies are round, glistening and whitish (cream-whitish in old colonies) when the cells are grown on meat-extract peptone agar [1]. Strain 7 $\mathrm{KIP}^{\mathrm{T}}$ is aerobic and Gram-positive (Gram-variable in old cultures) and not acid-fast [1]. Strain $7 \mathrm{KIP}^{\mathrm{T}}$ is rather fastidious in nutritional requirements [1]. Growth is seemingly dependent on some unidentified substances present in the peptone used in the growth medium [1]. The strain prefers complex me- dia for growth, especially containing peptone and yeast extract $[1,7]$. As such, the growth characteristics on a variety of media such as meat-extract peptone, blood serum broth, oatmeal agar, Sauton medium agar and other media, also in combination of different atmospheric gases and their concentrations, have been studied in detail [1]. Strain 7 KIPT is able to grow between $28^{\circ} \mathrm{C}$ and $37^{\circ} \mathrm{C}$, however, the cells grow faster at $37^{\circ} \mathrm{C}$ than $28^{\circ} \mathrm{C}$, but it does not at $45^{\circ} \mathrm{C}$ [1]. It grows slowly on meat-extract peptone medium and the first signs of macroscopic growth will appear after 3-5 days when incubated at $28^{\circ} \mathrm{C}$ [1]. Strain 7 KIPT $^{\mathrm{T}}$ does not grow on the majority of synthetic mineral media that are routinely used for actinomycetes [1,7]. Strain $7 \mathrm{KIP}^{\mathrm{T}}$ is able to reduce nitrate to nitrite when $\mathrm{KNO}_{3}$ is added to the growth medium (meat-extract peptone broth) [1]. The liquefaction of gelatin does not occur when the strain $7 \mathrm{KIP}^{\mathrm{T}}$ was grown on meat-extract peptone gelatine [1]. Strain $7 \mathrm{KIP}^{\mathrm{T}}$ has no antibiotic activity against Micrococcus luteus, Staphylococcus aureus, Escherichia coli, Bacillus subtilis, Candida albicans and Mycobacterium sp. v-5 [1].

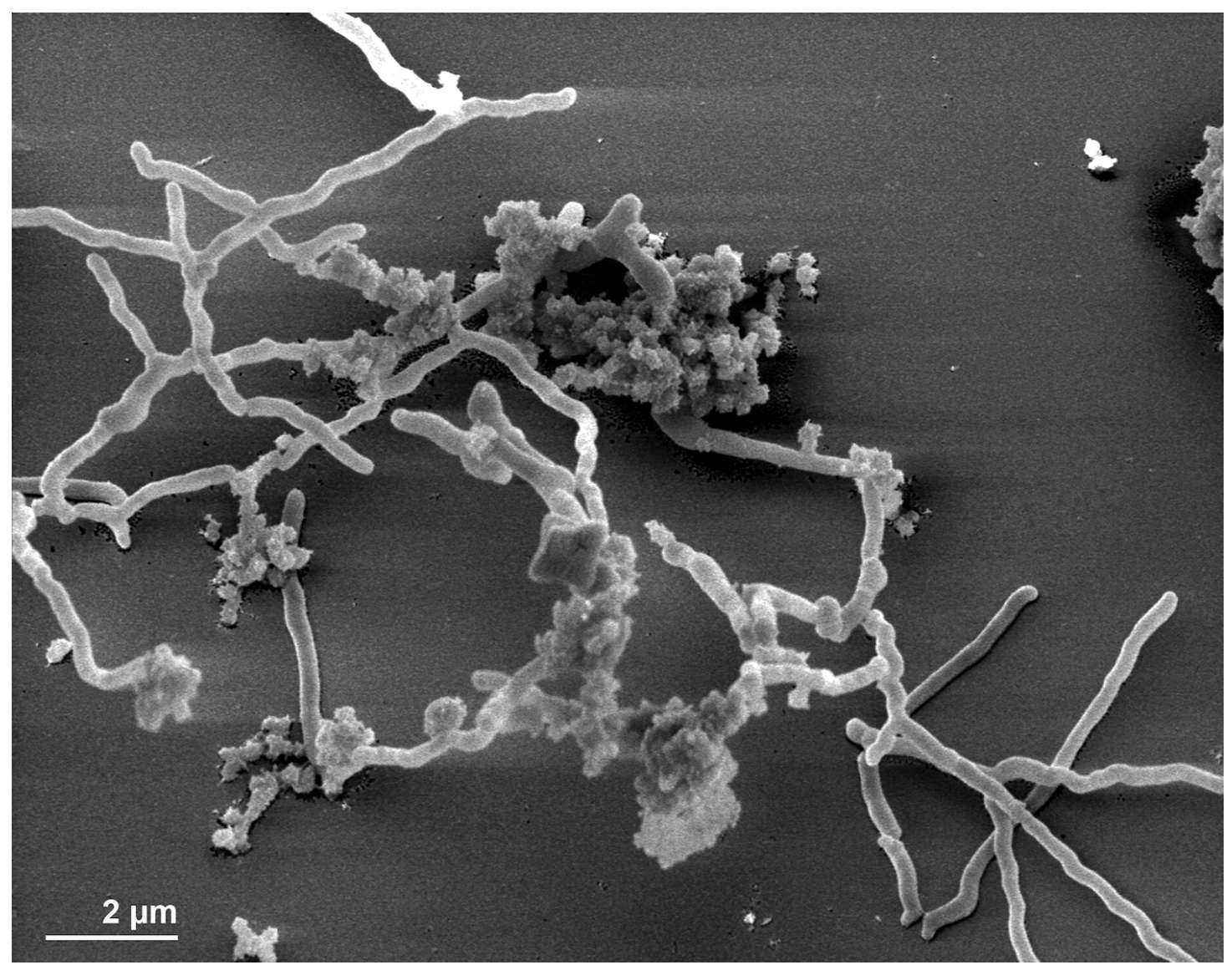

Figure 2. Scanning electron micrograph of I. calvum $7 \mathrm{KIP}^{\top}$ 
Glavina Del Rio et al.

Table 1. Classification and general features of I. calvum $7 \mathrm{KIP}^{\top}$ according to the MIGS recommendations [21].

\begin{tabular}{|c|c|c|c|}
\hline MIGS ID & Property & Term & Evidence code \\
\hline & \multirow{10}{*}{ Current classification } & Domain Bacteria & TAS [22] \\
\hline & & Phylum Actinobacteria & TAS [23] \\
\hline & & Class Actinobacteria & TAS $[4,24]$ \\
\hline & & Subclass Actinobacteridae & TAS $[4,6]$ \\
\hline & & Order Actinomycetales & TAS $[2,4,6,25]$ \\
\hline & & Suborder Micrococcineae & TAS $[4,6]$ \\
\hline & & Family Intrasporangiaceae & TAS $[4-6]$ \\
\hline & & Genus Intrasporangium & TAS $[1,2]$ \\
\hline & & Species Intrasporangium calvum & TAS $[1,2]$ \\
\hline & & Type strain 7 KIP & TAS [1] \\
\hline & Gram stain & positive & TAS [1] \\
\hline & Cell shape & $\begin{array}{l}\text { branching mycelium, which tends to break into } \\
\text { irregular fragments }\end{array}$ & TAS $[1,8]$ \\
\hline & Motility & none & TAS $[1,26]$ \\
\hline & Sporulation & none & TAS [26] \\
\hline & Temperature range & $28^{\circ} \mathrm{C}-37^{\circ} \mathrm{C}$ & TAS [1] \\
\hline & Optimum temperature & $37^{\circ} \mathrm{C}$ & NAS \\
\hline & Salinity & not reported & \\
\hline \multirow[t]{3}{*}{ MIGS-22 } & Oxygen requirement & aerobic & TAS $[1,7]$ \\
\hline & Carbon source & carbohydrates & TAS [1] \\
\hline & Energy source & chemoorganotroph & TAS $[1,7]$ \\
\hline MIGS-6 & Habitat & air & TAS [1] \\
\hline MIGS-15 & Biotic relationship & free-living & NAS \\
\hline \multirow[t]{3}{*}{ MIGS-14 } & Pathogenicity & none & NAS \\
\hline & Biosafety level & 1 & TAS [27] \\
\hline & Isolation & air in a school dining room & TAS [1] \\
\hline MIGS-4 & Geographic location & Russia & NAS \\
\hline MIGS-5 & Sample collection time & 1967 & TAS [1] \\
\hline MIGS-4.1 & Latitude & not reported & \\
\hline MIGS-4.2 & Longitude & not reported & \\
\hline MIGS-4.3 & Depth & not reported & \\
\hline MIGS-4.4 & Altitude & not reported & \\
\hline
\end{tabular}

Evidence codes - IDA: Inferred from Direct Assay (first time in publication); TAS: Traceable Author Statement (i.e., a direct report exists in the literature); NAS: Non-traceable Author Statement (i.e., not directly observed for the living, isolated sample, but based on a generally accepted property for the species, or anecdotal evidence). These evidence codes are from of the Gene Ontology project [28]. If the evidence code is IDA, then the property was directly observed by one of the authors or an expert mentioned in the acknowledgements.

\section{Chemotaxonomy}

Strain 7 KIPT $^{\mathrm{T}}$ contains LL-diaminopimelic acid (LL$\mathrm{A}_{2} \mathrm{pm}$ ) in the cell wall and possesses the A3 $\gamma$-type of peptidoglycan $[29,30]$. The amino acid at position 1 of the peptide subunit is L-alanine [30]. The cell wall structure of strain $7 \mathrm{KIPT}^{\mathrm{T}}$ is characterized by the cross-linkage of the A3 $\gamma$-type peptidoglycan via a triglycine-interpeptide bridge and by a glycine residue bound to the $\alpha$-carboxyl group of the D-glutamic acid position 2 of the peptide subunit $[29,30]$. Strain $7 \mathrm{KIPT}^{\mathrm{T}}$ possesses a totally unsaturated menaquinone with eight isoprene units
(MK-8) instead of a partially saturated menaquinone with two of eight isoprene units hydrogenated $\left(\mathrm{MK}-8\left(\mathrm{H}_{4}\right)\right)$ which is the characteristic menaquinone of all other representatives of the family Intrasporangiaceae [8,30]. Cells of strain $7 \mathrm{KIP}^{\mathrm{T}}$ contain glucosamine-containing phospholipids (phospholipids type 4) [7]. Polar lipids of the strain are phosphatidyl-inositol, phosphatidylinositol mannosides, phosphatidylglycerol and diphosphatidyl-glycerol [30]. The major cellular fatty acids are saturated branched-chain acids: iso- 
$\mathrm{C}_{15: 0} \quad(37.8 \%)$, anteiso- $\mathrm{C}_{15: 0}(12.6 \%)$, iso- $\mathrm{C}_{16: 0}$ (12.3\%), iso- $\mathrm{C}_{14: 0}(5.0 \%)$, anteiso- $\mathrm{C}_{17: 0}(3.9 \%)$, iso$\mathrm{C}_{17: 1}(3.7 \%)$, iso- $\mathrm{C}_{15: 1}(3.5 \%)$, iso- $\mathrm{C}_{16: 1}(3.1 \%)$ and straight chain acid $\mathrm{C}_{15: 0}$ (2.7\%) [30]. Polyamine contents ( $\mu \mathrm{mol}$ per $\mathrm{g}$ dry $w \mathrm{t})$ of strain $7 \mathrm{KIP}^{\mathrm{T}}$ are putrescine (2.02), spermidine (1.03), spermine (0.31), cadaverine (0.30), 1,3-diaminopropane (0.17), sym-homospermidine (0.05) and tyramine (0.17) [29].

\section{Genome sequencing and annotation Genome project history}

This organism was selected for sequencing on the basis of its phylogenetic position [31], and is part of the Genomic Encyclopedia of Bacteria and Archaea project [32]. The genome project is deposited in the Genome OnLine Database [19] and the complete genome sequence is deposited in GenBank. Sequencing, finishing and annotation were performed by the DOE Joint Genome Institute (JGI). A summary of the project information is shown in Table 2.

Table 2. Genome sequencing project information

\begin{tabular}{|c|c|c|}
\hline MIGS ID & Property & Term \\
\hline MIGS-31 & Finishing quality & Finished \\
\hline MIGS-28 & Libraries used & $\begin{array}{l}\text { Three genomic libraries: one standard and one paired ended } 454 \\
\text { pyrosequence library and one standard Illumina library }\end{array}$ \\
\hline MIGS-29 & Sequencing platforms & 454 GS FLX Titanium, Illumina GAii \\
\hline MIGS-31.2 & Sequencing coverage & $59.7 \times$ pyrosequence: $95.2 \times$ Illumina \\
\hline MIGS-30 & Assemblers & Newbler version 2.0.0-PostRelease-11/04/2008, phrap \\
\hline \multirow[t]{6}{*}{ MIGS-32 } & Gene calling method & Prodigal 1.4, GenePRIMP \\
\hline & INSDC ID & СР002343 \\
\hline & Genbank Date of Release & December 29, 2010 \\
\hline & GOLD ID & Gc01572 \\
\hline & NCBI project ID & 43527 \\
\hline & Database: IMG-GEBA & 2503538011 \\
\hline \multirow[t]{2}{*}{ MIGS-13 } & Source material identifier & DSM 43043 \\
\hline & Project relevance & Tree of Life, GEBA \\
\hline
\end{tabular}

\section{Growth conditions and DNA isolation}

I. calvum $7 \mathrm{KIP}^{\mathrm{T}}$ was grown in medium 65 (GYM Streptomycetes medium) supplemented with one third of BHI (medium 215) [33] at $28^{\circ} \mathrm{C}$. DNA was isolated from 0.5-1 g of cell paste using Qiagen Genomic 500 DNA Kit (Qiagen, Hilden, Germany) following the standard protocol as recommended by the manufacturer, with modification st/LALMP for cell lysis as described by Wu et al. [32].

\section{Genome sequencing and assembly}

The genome was sequenced using a combination of Illumina and 454 sequencing platforms. All general aspects of library construction and sequencing can be found at the JGI website [34]. Pyrosequencing reads were assembled using the Newbler assembler version 2.0.0-PostRelease11/04/2008 (Roche). The initial Newbler assembly consisted of 28 contigs in two scaffolds and was converted into a phrap assembly by making fake reads from the consensus, collecting the read pairs in the 454 paired end library. Illumina GAii sequencing data (309MB) was assembled with Velvet [35] and the consensus sequences were shredded into $1.5 \mathrm{~kb}$ overlapped fake reads and assembled together with the 454 data. The 454 draft assembly was based on $226.2 \mathrm{Mb} 454 \mathrm{draft}$ data and all of the 454 paired end data. Newbler parameters are -consed -a 50 -l 350 -g -m -ml 20. The Phred/Phrap/Consed software package [36] was used for sequence assembly and quality assessment in the following finishing process. After the shotgun stage, reads were assembled with parallel phrap (High Performance Software, LLC). Possible mis-assemblies were corrected with gapResolution [34], Dupfinisher, or sequencing cloned bridging PCR fragments with subcloning or 
transposon bombing (Epicentre Biotechnologies, Madison, WI) [20]. Gaps between contigs were closed by editing in Consed, by PCR and by Bubble PCR primer walks (J.-F.Chang, unpublished). A total of 139 additional reactions were necessary to close gaps and to raise the quality of the finished sequence. Illumina reads were also used to correct potential base errors and increase consensus quality using a software Polisher developed at JGI [37]. The error rate of the completed genome sequence is less than one error in 100,000. Together, the combination of the Illumina and 454 sequencing platforms provided $154.9 \times$ coverage of the genome. The final assembly contains 847,906 pyrosequencing and 11,758,818 Illumina reads.

\section{Genome annotation}

Genes were identified using Prodigal [38] as part of the Oak Ridge National Laboratory genome annotation pipeline, followed by a round of manual curation using the JGI GenePRIMP pipeline [39].
The predicted CDSs were translated and used to search the National Center for Biotechnology Information (NCBI) nonredundant database, UniProt, TIGRFam, Pfam, PRIAM, KEGG, COG, and InterPro databases. Additional gene prediction analysis and functional annotation was performed within the Integrated Microbial Genomes - Expert Review (IMG-ER) platform [40].

\section{Genome properties}

The genome consists of a 4,024,382 bp long chromosome with a $70.7 \%$ GC content (Table 3 and Figure 3). Of the 3,710 genes predicted, 3,653 were protein-coding genes, and 57 RNAs; ninety pseudogenes were also identified. The majority of the protein-coding genes $(71.3 \%)$ were assigned with a putative function while the remaining ones were annotated as hypothetical proteins. The distribution of genes into COGs functional categories is presented in Table 4.

Table 3. Genome Statistics

\begin{tabular}{lrr}
\hline Attribute & Value & \% of Total \\
\hline Genome size (bp) & $4,024,382$ & $100.00 \%$ \\
DNA coding region (bp) & $3,618,708$ & $89.92 \%$ \\
DNA G+C content (bp) & $2,845,385$ & $70.70 \%$ \\
Number of replicons & 1 & \\
Extrachromosomal elements & 0 & \\
Total genes & 3,710 & $100.00 \%$ \\
RNA genes & 57 & $1.54 \%$ \\
rRNA operons & 2 & \\
Protein-coding genes & 3,653 & $98.46 \%$ \\
Pseudo genes & 90 & $2.43 \%$ \\
Genes with function prediction & 2,645 & $71.29 \%$ \\
Genes in paralog clusters & 360 & $7.70 \%$ \\
Genes assigned to COGs & 2,674 & $72.08 \%$ \\
Genes assigned Pfam domains & 2,871 & $77.39 \%$ \\
Genes with signal peptides & 1,101 & $29.68 \%$ \\
Genes with transmembrane helices & 860 & $23.18 \%$ \\
CRISPR repeats & 0 & \\
\hline
\end{tabular}




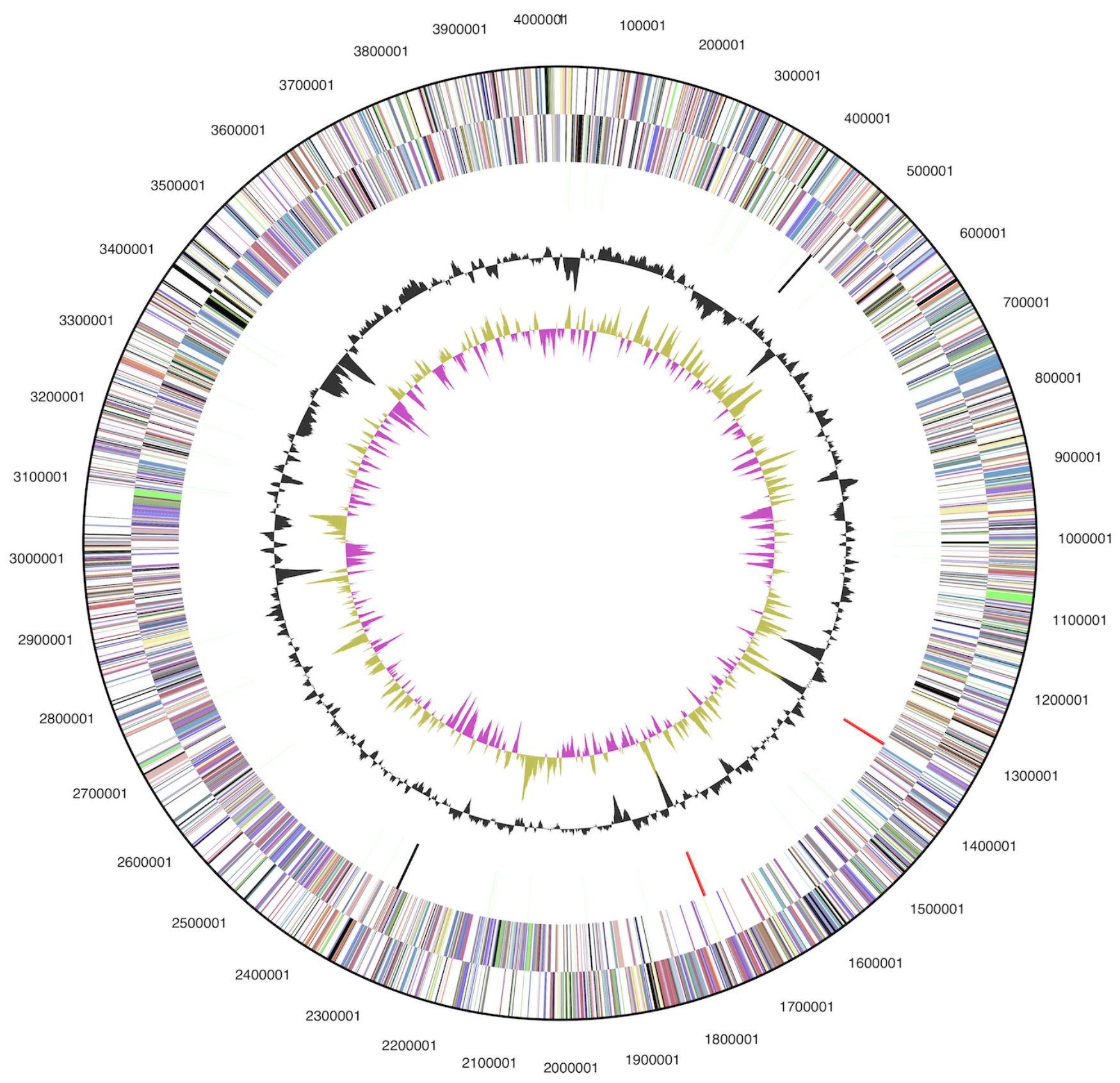

Figure 3. Graphical circular map of the genome. From outside to the center: Genes on forward strand (color by COG categories), Genes on reverse strand (color by COG categories), RNA genes (tRNAs green, rRNAs red, other RNAs black), GC content, GC skew. 
Table 4. Number of genes associated with the general COG functional categories

\begin{tabular}{lrrl}
\hline Code & value & \%age & Description \\
\hline J & 160 & 5.4 & Translation, ribosomal structure and biogenesis \\
A & 1 & 0.0 & RNA processing and modification \\
K & 230 & 7.8 & Transcription \\
L & 181 & 6.1 & Replication, recombination and repair \\
B & 2 & 0.1 & Chromatin structure and dynamics \\
D & 38 & 1.3 & Cell cycle control, cell division, chromosome partitioning \\
Y & 0 & 0.0 & Nuclear structure \\
V & 46 & 1.6 & Defense mechanisms \\
T & 131 & 4.4 & Signal transduction mechanisms \\
M & 155 & 5.2 & Cell wall/membrane/envelope biogenesis \\
N & 2 & 0.1 & Cell motility \\
Z & 0 & 0.0 & Cytoskeleton \\
W & 0 & 0.0 & Extracellular structures \\
U & 34 & 1.2 & Intracellular trafficking and secretion, and vesicular transport \\
O & 98 & 3.3 & Posttranslational modification, protein turnover, chaperones \\
C & 223 & 7.5 & Energy production and conversion \\
G & 199 & 6.7 & Carbohydrate transport and metabolism \\
E & 305 & 10.3 & Amino acid transport and metabolism \\
F & 79 & 2.7 & Nucleotide transport and metabolism \\
H & 141 & 4.8 & Coenzyme transport and metabolism \\
I & 151 & 5.1 & Lipid transport and metabolism \\
P & 132 & 4.5 & Inorganic ion transport and metabolism \\
Q & 89 & 3.0 & Secondary metabolites biosynthesis, transport and catabolism \\
R & 358 & 12.1 & General function prediction only \\
S & 212 & 7.2 & Function unknown \\
- & 1,036 & 27.9 & Not in COGs \\
\hline & & &
\end{tabular}

\section{Acknowledgements}

We would like to gratefully acknowledge the help of Gabriele Gehrich-Schröter for growing I. calvum cultures and Susanne Schneider for DNA extraction and quality analysis (both at DSMZ). This work was performed under the auspices of the US Department of Energy's Office of Science, Biological and Environmental Research Program, and by the University of California, Lawrence Berkeley National Laboratory under contract No. DE-AC02-05CH11231, Lawrence Livermore
National Laboratory under Contract No. DE-AC5207NA27344, and Los Alamos National Laboratory under contract No. DE-AC02-06NA25396, UT-Battelle and Oak Ridge National Laboratory under contract DEAC05-000R22725, as well as German Research Foundation (DFG) INST 599/1-2 and SI 1352/1-2, and Thailand Research Fund Royal Golden Jubilee Ph.D. Program No. PHD/0019/2548' for MY.

\section{References}

1. Kalakoutskii LV, Kirillova IP, Krassilnikov NA. A new genus of the Actinomycetales - Intrasporangium gen. nov. J Gen Microbiol 1967; 48:79-85.

2. Skerman VBD, McGowan V, Sneath PHA. Approved lists of bacterial names. Int J Syst Bacteriol 1980; 30:225-420. doi:10.1099/00207713-30-1$\underline{225}$ 
3. Kalakoutslii LV. Genus Intrasporangium. In: Bergey's Manual of Systematic Bacteriology. Vol. 2. PHA Sneath, NS Mair, ME Sharpe, JG Holt (eds). p. 1504-1506. Williams \& Wilkins, 1986. Baltimore, USA

4. Stackebrandt E, Rainey FA, Ward NL. Proposal for a new hierarchic classification system, Actinobacteria classis nov. Int I Syst Bacteriol 1997; 47:479491. doi:10.1099/00207713-47-2-479

5. Stackebrandt E, Schumann P. Description of Bogoriellaceae fam. nov., Dermacoccaceae fam. nov., Rarobacteraceae fam. nov. and Sanguibacteraceae fam. nov. and emendation of some families of the suborder Micrococcineae. Int J Syst Evol Microbiol 2000; 50:1279-1285. PubMed

6. Zhi XY, Li WJ, Stackebrandt E. An update of the structure and $16 \mathrm{~S}$ rRNA gene sequence-based definition of higher ranks of the class Actinobacteria, with the proposal of two new suborders and four new families and emended descriptions of the existing higher taxa. Int I Syst Evol Microbiol 2009; 59:589-608. PubMed doi:10.1099/ijs.0.65780-0

7. Holt JG, Krieg NR, Sneath PHA, Staley JT, Williams ST. 1994. Bergey's Manual of Determinative Bacteriology, 9th ed. Williams \& Wilkins, Baltimore.

8. Stackebrandt E, Schumann P. 2006. Archaea. Bacteria: Firmicutes, Actinomycetes, p. 297-321. In M Dworkin, S Falkow, E Rosenberg, K-H Schleifer, E Stackebrandt (eds), The Prokaryotes: A Handbook on the Biology of Bacteria, Vol. 3. Springer Science + Business Media LLC, New York, printed in Singapore

9. Chun J, Lee JH, Jung Y, Kim M, Kim S, Kim BK, Lim YW. EzTaxon: a web-based tool for the identification of prokaryotes based on 165 ribosomal RNA gene sequences. Int / Syst Evol Microbiol 2007; 57:2259-2261. PubMed doi:10.1099/ijs.0.64915-0

10. Benson DA, Karsch-Mizrachi I, Lipman DJ, Ostell J, Sayers EW. GenBank. Nucleic Acids Res 2009; 37:D26-D31. PubMed doi:10.1093/nar/gkn723

11. Kunapuli U, Lueders T, Meckenstock RU. The use of stable isotope probing to identify key ironreducing microorganisms involved in anaerobic benzene degradation. ISME J 2007; 1:643-653. PubMed doi:10.1038/ismej.2007.73

12. Brodie EL, Desantis TZ, Joyner DC, Baek SM, Larsen JT, Andersen GL, Hazen TC, Richardson PM, Herman DJ, Tokunaga TK, et al. Application of a high-density oligonucleotide microarray approach to study bacterial population dynamics during uranium reduction and reoxidation. App/ Environ Microbiol 2006; 72:6288-6298. PubMed doi:10.1128/AEM.00246-06

13. DeSantis TZ, Hugenholtz $\mathrm{P}$, Larsen N, Rojas $M$, Brodie EL, Keller K, Huber T, Dalevi D, Hu P, Andersen GL. Greengenes, a chimera-checked $16 \mathrm{~S}$ rRNA gene database and workbench compatible with ARB. App/ Environ Microbiol 2006; 72:5069-5072. PubMed doi:10.1128/AEM.03006-05

14. Castresana J. Selection of conserved blocks from multiple alignments for their use in phylogenetic analysis. Mol Biol Evol 2000; 17:540-552. $\underline{\text { PubMed }}$

15. Lee C, Grasso C, Sharlow MF. Multiple sequence alignment using partial order graphs. BioinformatiCs 2002; 18:452-464. PubMed doi:10.1093/bioinformatics/18.3.452

16. Stamatakis A, Hoover P, Rougemont J. A rapid bootstrap algorithm for the RAxML Web servers. Syst Biol 2008; 57:758-771. PubMed doi:10.1080/10635150802429642

17. Yarza P, Richter M, Peplies J, Euzeby J, Amann R, Schleifer KH, Ludwig W, Glöckner FO, RossellóMóra R. The All-Species Living Tree project: A $16 \mathrm{~S}$ rRNA-based phylogenetic tree of all sequenced type strains. Syst Appl Microbiol 2008; 31:241-250. PubMed doi:10.1016/j.syapm.2008.07.001

18. Pattengale ND, Alipour M, Bininda-Emonds ORP, Moret BME, Stamatakis A. How many bootstrap replicates are necessary? Lect Notes Comput Sci 2009; 5541:184-200. doi:10.1007/978-3-642$\underline{02008-7 \quad 13}$

19. Liolios K, Chen IM, Mavromatis K, Tavernarakis N, Hugenholtz P, Markowitz VM, Kyrpides NC. The Genomes On Line Database (GOLD) in 2009: status of genomic and metagenomic projects and their associated metadata. Nucleic Acids Res 2009; 38:D346-D354. PubMed doi:10.1093/nar/gkp848

20. Sims D, Brettin T, Detter JC, Han C, Lapidus A, Copeland A, Glavina Del Rio T, Nolan M, Chen $\mathrm{F}$, Lucas $\mathrm{S}$, et al. Complete genome sequence of Kytococcus sedentarius type strain $\left(541^{\top}\right)$. Stand Genomic Sci 2009; 1:12-20. doi:10.4056/sigs.761

21. Field D, Garrity G, Gray T, Morrison N, Selengut J, Sterk P, Tatusova T, Thomson N, Allen MJ, Angiuoli $S V$, et al. The minimum information about a genome sequence (MIGS) specification. Nat 
Biotechnol 2008; 26:541-547. PubMed

doi:10.1038/nbt1360

22. Woese CR, Kandler O, Wheelis ML. Towards a natural system of organisms: proposal for the domains Archaea, Bacteria, and Eucarya. Proc Natl Acad Sci USA 1990; 87:4576-4579. PubMed doi:10.1073/pnas.87.12.4576

23. Garrity GM, Holt JG. The Road Map to the Manual. In: Garrity GM, Boone DR, Castenholz RW (eds), Bergey's Manual of Systematic Bacteriology, Second Edition, Volume 1, Springer, New York, 2001, p. 119-169.

24. Euzéby JP, Tindall BJ. Nomenclatural type of orders: corrections necessary according to Rules 15 and 21a of the Bacteriological Code (1990 Revision), and designation of appropriate nomenclatural types of classes and subclasses. Request for an opinion. Int J Syst Evol Microbiol 2001; 51:725-727. PubMed

25. Buchanan RE. Studies in the nomenclature and classification of bacteria. II. The primary subdivisions of the Schizomycetes. J Bacteriol 1917; 2:155-164. PubMed

26. Lechevalier H, Lechevalier MP. Ultramicroscopic structure of Intrasporangium calvum (Actinomycetales). J Bacteriol 1969; 100:522-525. PubMed

27 Classification of bacteria and archaea in risk groups. TRBA 466.

28. Ashburner M, Ball CA, Blake JA, Botstein D, Butler H, Cherry JM, Davis AP, Dolinski K, Dwight SS, Eppig JT, et al. Gene Ontology: tool for the unification of biology. Nat Genet 2000; 25:25-29. PubMed doi:10.1038/75556

29. Busse HJ, Schumann P. Polyamine profiles within genera of the class Actinobacteria with LLdiaminopimelic acid in the peptidoglycan. Int J Syst Bacteriol 1999; 49:179-184. PubMed doi:10.1099/00207713-49-1-179

30. Schumann P, Prauser H, Rainey FA, Stackebrandt E, Hirsch P. Friedmanniella antarctica gen. nov., sp. nov., an LL-diaminopimelic acid-containing actinomycete from Antarctic sandstone. Int / Syst
Bacteriol 1997; 47:278-283. PubMed

doi:10.1099/00207713-47-2-278

31. Klenk HP, Goeker M. En route to a genome-based classification of Archaea and Bacteria? Syst Appl Microbiol 2010; 33:175-182. PubMed doi:10.1016/j.syapm.2010.03.003

32. Wu D, Hugenholtz $P$, Mavromatis K, Pukall R, Dalin E, Ivanova NN, Kunin V, Goodwin L, Wu $M$, Tindall BJ, et al. A phylogeny-driven genomic encyclopaedia of Bacteria and Archaea. Nature 2009; 462:1056-1060. PubMed doi:10.1038/nature08656

33. List of growth media used at DSMZ: http://www.dsmz.de/microorganisms/media_list.p hp.

34. DOE Joint Genome Institute. http://www.jgi.doe.gov

35. Zerbino DR, Birney E. Velvet: algorithms for de novo short read assembly using deBruijn graphs. Genome Res 2008; 18:821-829. PubMed doi:10.1101/gr.074492.107

36. Phrap and Phred for Windows. MacOS, Linux, and Unix. http://www.phrap.com

37. Lapidus A, LaButti K, Foster B, Lowry S, Trong S, Goltsman E. POLISHER: An effective tool for using ultra short reads in microbial genome assembly and finishing. AGBT, Marco Island, FL, 2008.

38. Hyatt D, Chen GL, Locascio PF, Land ML, Larimer FW, Hauser LJ. Prodigal: prokaryotic gene recognition and translation initiation site identification. BMC Bioinformatics 2010; 11:119. PubMed doi:10.1186/1471-2105-11-119

39. Pati A, Ivanova NN, Mikhailova N, Ovchinnikova G, Hooper SD, Lykidis A, Kyrpides NC. GenePRIMP: a gene prediction improvement pipeline for prokaryotic genomes. Nat Methods 2010; 7:455-457. PubMed doi:10.1038/nmeth.1457

40. Markowitz VM, Ivanova NN, Chen IMA, Chu K, Kyrpides NC. IMG ER: a system for microbial genome annotation expert review and curation. Bioinformatics 2009; 25:2271-2278. PubMed doi:10.1093/bioinformatics/btp393 